\title{
Inhibition tests and study of metabolites in fungi that deteriorate stony materials
}

\author{
Wafaa Mohamed Masoud EI Faras \\ Alexandria University -Egypt \\ Email:welfaras@yahoo.com \\ DOI: 10.46617/icbe7002
}

\begin{abstract}
A group of different fungi isolated from many kinds of Spanish monuments was used in present study. This work focused on three main objectives:

A) Metabolism of fungi harboring the stones by means of HPLC.

B) Study effect of four biocides, i.e. Actidide, Meragel, Preventol, and Tego on fungal growth and sporulation.

C) Electronic microscopy examination of the growth of those fungi on the stones.

The results showed that some phenolic acids, i.e. Gallic acid, Caffeic Acid, Gentisic acid, Vanillic acid, Coumaric acid, Ferulic acid, 4hidroxy benzoic acid, and 4hidroxy-phenyl propionic acid, were produced. Electronic microscopy examination showed inhibition of the fungi growth and changes of their morphology and structure. Also, results postulated that Actidide was the best biocide for controlling growth of the tested fungi at concentration of $0.001 \%$.
\end{abstract}

Key words: Fungi, Biocides, Biodeterioration, phenolic acids, Actidide.

DOI:

\section{Introduction}

All stony materials exposed to the action of the Nature deteriorate continuously as a result of the action of physical, chemical and biological agents. For several decades many monuments that have in their life over many years, they are suffering a much more intense wear due to undoubtedly, aggressive action of atmospheric pollutants. The problem is more serious since most of the historical buildings are located in urban areas and close to industrial centers. In these areas the continuous emission of pollutants from explosion engines and factories, causes the expulsion of gaseous compounds and particles of different nature, $\mathrm{SO} 2, \mathrm{CO} 2, \mathrm{~N}$ oxides, etc., which are adhere to the surface of the stones, being able interact with it (1). This causes several 
problems. On the one hand, the prolonged adhesion of particles on the monuments it creates blackish skates that damage the value aesthetic of the monument. On the other hand, some pollutants deposited, in the presence of moisture, produce compounds highly reactive (H2SO4, HNO3, etc.) that damage the structure of the stone (2). Although, generally, atmospheric pollutants are harmful to organisms, sometimes they can promote microbe's growth. Regarding this, it has been proven that kerosene, one product obtained from oil and consisting of a mixture of hydrocarbons, added to the culture medium, was tabulated and used as a source of Carbone and energy for chemoorganotrophic bacteria (3). Biological agents have long been known (algae, lichens, fungi, bacteria and even higher plants) have an extensive community capable of carrying out chemical and mineral modifications in the different types of rocks and minerals (4,5, and 6). They not only can live on the surface of stony materials but that through the cracks and fissures that often present the walls or the cracks that some organisms penetrate inside and continue their developing and metabolic activity (7). The incidence of microorganisms on materials stony is variable and depends on your metabolic abilities and also, to a large extent, of climatic factors and environmental. Therefore, the study and understanding of the role of microorganisms, and of course fungi, is complex and the numerous interrelationships between the microbial populations and the physical and chemical factors of ambient.

The main source of stone contamination is the soil and through different mechanisms air, humidity, insects, etc., many of these organisms settle and multiply on the stone. Fungi are heterotrophic organisms adapted to live in stone and living together with autotrophic organisms and heterotrophs, forming _ associations, in many houses, synergistic. In addition, yes, due to the hyphae system that develops and the ability to metabolize many polyacids, can be present in fissures, cracks and other cavities of the stone. Fungi have different mechanisms of biodeterioration that can be grouped into two categories: physical and chemical. Due to the physical activity of the hyphae and the pressure exerted during growth can produce fracturing and breaking of minerals and stone. Chemical processes involve deterioration caused by metabolic products. These processes are developed mainly in two ways: through the production of organic and inorganic acids that acidify the media thus favoring the processes of dissolution of the cations minerals. fungi have been found to produce acidity carbonic, nitric, etc. and many other organic acids during their metabolism, such as citric, oxalic, fumaric, gluconic, etc. (8 , 9 , and 10). This leads to the formation of salts. organic oxalate, citrate, gluconate, etc., which precipitate and it was deposited on the surface of the minerals. Other Mechanism of alteration is the complexes of chelation that 'for example' many organic acids form excreted by fungi with trivalent cations, thus keeping them in solution (11). A group of different fungi isolated from many kinds of Spanish monuments was used in present study. This work focused on three main objectives: 1-Metabolism of fungi harbored in the stones by means of HPLC. 2-Study effect of four biocides, i.e. Actidide, Meragel, Preventol, and Tego on fungal growth and sporulation. 3Electronic microscopy examination of the growth of those fungi on the stones.

\section{Materials and Methods}

\subsection{Culture media}


The microorganisms used were kept in the laboratory in tubes with inclined malt extract agar, periodically replanting on the same medium and incubating in an oven at 28 "for 7 days to achieve good growth and sporulation. For the conservation of the cultures, paraffin oil that was poured onto the culture of the fungi grown on malt agar to cover the upper end of the agar. The culture medium used was the Czapek-Dox medium (12)

The glucose solutions are distributed in $100 \mathrm{ml}$ flasks, also containing $10 \mathrm{ml}$. Sterilization is carried out by flowing steam for 30 minutes, in 3 consecutive days, to avoid the decomposition of glucose. Finally, and under sterile conditions, the saline solution and the glucose solution are mixed in the convenient proportions, to obtain the desired concentration.

\subsection{Microorganisms}

Organisms isolated from crusts and altered surfaces from the cathedrals of Salamanca and Toledo that belong to the culture collection of the C.I.B. The tested bongos are grouped into the following species and genera:

\section{-Aspergillus niger}

-Fusarium oxysporum

-Penicillium frequentans

-Penicillium steckii

-Trichoderma pseudo koningii Rifai

-Trichoderma viride

-Alternaria alternata

-Phoma glomerata

-Phoma eupyrena

-Mucor hiemalis

\subsection{Reagents}

The reagents used in these experiments were the majority of "analytical grade", with the exception of the mineral salts used in the preparation of the culture medium, which were of "reactive grade".

\subsubsection{Preparation of the inoculum}


From the agar-malt fugal cultures, spore suspensions are prepared. To do this, $10 \mathrm{ml}$ of sterile water containing $0.01 \%$ Tween 80 was poured into the solid cultures and the surface was scraped with a platinum handle to obtain the desired spore suspension. Then performed a spore count on a camera counting blood cells "Thoma", adjusting the concentration to $10^{5}-10^{6}$ cells $/ \mathrm{ml}$.

\subsubsection{Growing conditions}

For the cultivation of the fungi, the Czapek Dox medic with 3\% glucose was used. The media was divided into $20 \mathrm{ml}$ fractions in $100 \mathrm{ml}$ Erlenmeyer flasks and inoculated with $1 \mathrm{ml}$ of spore suspension from each fungal culture. After 14 days of incubation at $27^{\circ} \mathrm{C}$ and in the dark, the medic was filtered, the volume was completed to $20 \mathrm{ml}$ and the $\mathrm{pH}$ was determined on a Crison digital pH meter, mod. 501.

\subsubsection{Preparation of samples for high performance liquid chromatography (HPLC).}

After the established culture periods, the samples with fungal culture were filtered through Whatman No 1 paper and the $\mathrm{pH}$ in the filtered liquids was measured. Subsequently, the cultures were centrifuged at 7,000 r.p.m. for 20 minutes and the supernatant was subjected, again, to a second filtration through a $0.22 \mathrm{pm}$ pore diameter Millipore membrane. Finally, the filters were frozen until use. $5 \mathrm{ml}$ of each sample was concentrated to dryness on a rotary evaporator. $0.2 \mathrm{ml}$ of concentrated $\mathrm{HCl}$ and $0.6 \mathrm{ml}$ of ethyl ether were added to the residue. Shake well and after a period of rest two phases separate. The ether phase is collected and again dried on a rotary evaporator. The sediment is dissolved in $100 \mathrm{ul}$ of (Acetic acid: water, 9:98 v / v). Centrifuge 5 minutes at 12,000 r.p.m. centrifuge leaks microfuge and is injected into the chromatograph or 10 or $20 \mathrm{ul}$, according to the cases.

\subsubsection{The phenolic acids used as standards were as follows:}

Gallic acid

4-hydroxy-benzoic acid

Gentisic acid

Caffeic acid

Vanillic acid

Syringic acid 
4-hydroxyphenylpropionic acid

Acid p. coumaric

Ferulic acid

Standard concentration solutions of $1 \mathrm{mg} / \mathrm{ml}$ were prepared and 5 and $10 \mathrm{pl}$ of each of them were injected, separately. In addition, a mix of the 9 patterns was prepared, which was also infected and whose chromatographic branches served as a reference for our problems.

\subsubsection{Quantitative analysis of phenolic acids.}

Perkin-Elmer HPLC chromatography, 2B series with ultraviolet detector was used together with a 250 × $46 \mathrm{~mm}$ Ultrasphere ODS reversed phase column. As gradient, 2 gradient solutions were used. Solution A contained acetic: Milly Q water (9:98 v / v) and solution B consisted of acetic: methanol: water $(1: 15: 34 \mathrm{v} / \mathrm{v})$. The fixed outflow was $0.2 \mathrm{ml} / \mathrm{min}$. The infection volume was $10-20 \mu \mathrm{l}$ and the wavelength used was $220 \mathrm{pm}$.

\subsection{Biocides}

Four biocides were selected to test their inhibition capacity against several isolated fungal strains of altered stone monuments. The interest for the study of these products lies in the fact that they have been used, in their majority, in some countries, together with restoration products, such as supporters and protectors. Biocide samples were donated to the laboratory or the following manufacturers or distributors:

\begin{tabular}{|l|l|l|}
\hline \multicolumn{1}{|c|}{ Biocides } & \multicolumn{1}{|c|}{$\begin{array}{c}\text { Biocide Manufacturer or } \\
\text { distributor }\end{array}$} & \multicolumn{1}{c|}{ Active ingredients } \\
\hline Actidide DW & Core salt & Mixture of cyclic derivates \\
\hline Mergal V 540 & Hoechst Iberica & Triazine and Anunonia derivatives \\
\hline Tego 518 & T.H. Goldschmidt, S.A & $\begin{array}{l}\text { Alkyl Dimeth yl Benzil Ammonium } \\
\text { chloride }\end{array}$ \\
\hline Preventol R 80 & Bayer, S.A & \\
\hline
\end{tabular}

Diluted solutions of each product were prepared in the appropriate solvent, Actidide in ethanol and the rest in water, so that when added to the Petri dishes, the following final concentrations were reached: $0.001,0.01,0.05$ and 0.1 . 


\subsection{Study of fungal growth under a scanning electron microscope (SEM).}

A Hitachi scanning electron microscope was used in present study. Intact sandstone specimens, about $1 \times 1 \times 0.5 \mathrm{~cm}$, were prepared and washed and sterilized at 100 'C for 3 days. Spore suspensions of the two strains selected for this study were prepared: Fusarium sp. and Aspergillus niger. The suspensions were made in sterile water with $0.01 \% \%$ tween, adjusting cells concentration to $10^{5}-10^{6}$ spores $/ \mathrm{ml}$.

\section{Results and Discussion}

Phenolic acids together with flavonoids are their components of the humic substances that are formed during the decomposition of organic residues in the soil, for this reason, phenolic compounds of low $\mathrm{pH}$, appear widely in soils (13). Furthermore, they are also products of microbial metabolism (14). For this reason, in this work we have carried out a study to know the phenolic acids produced by acidogenic and non-acidogenic fungi that had been isolated from Spanish historical monuments. Phenolic acids produced in glucose metabolism were determined by liquid chromatography (HPLC).

\subsection{Phenolic acids production:}

Table (1) shows the phenolic acids that we have identified by liquid chromatography in the metabolic broths of the fungi. The profile of phenolic acids is shown. There it is observed that Fusarium sp. was the fungus that produced the largest number of different acids and also, generally, in the greatest quantity. P. steckii, A. alternata and P. eupyrena followed. On the other hand, the glycol was excreted for all strains studied, followed by the ferulic that was produced by 5 fungi. Most of these acids and also different ones were identified by Martin and Haider (1969) [15] in the Stachybotrys atra, S. chartarum and Epicoccum nigrum cultures growing in media where glucose was the main hydrocarbon component. The absence of some phenols in metabolic broths does not mean that they were not initially synthesized, since it has been found that a wide range of aromatic acids, phenolic acids, etc., can be used as a source of $\mathrm{C}$ for many microorganisms [16]. Other works have shown a certain mineral activity of phenolic acids. Robert and Razzaghe-Karimi (1975) [17] found that various types of micas were altered when subjected to the action of p-hydroxybenzoic and vanillic. The remaining fungi tested and cited in Table (1) are not acidogenic, however they synthesize phenols, and in greater quantity, in some cases, than acidogenic fungi, such as Fusarium $s p$. Since the microorganisms do not appear, in an ecological niche, as unique species, but in coexistence with other organisms, sometimes forming microbial consortia, it is possible to think that the complexing effect of these nonacidogenic fungi is favored by the proximity of other fungi and other classes of organisms. 
Proceeding of $7^{\text {th }}$ International Conference of Biotechnology, Environment and Engineering Sciences and

The International Conference of Data Mining and Software Development 26 June 2020, Stockholm - Sweden

Table (1) :Phenolic acids production (mg / L) for different fungi cultivated on Czapek Dox with $3 \%$ glucose during 14 days.

\begin{tabular}{|c|c|c|c|c|c|c|c|c|c|}
\hline Fungi & GAL & $\mathrm{CAF}$ & FER & $\begin{array}{c}\text { GEN } \\
\text { and / or } \\
4 \mathrm{HB}\end{array}$ & VAN & CUM & $4 \mathrm{HF}$ & Total & $\begin{array}{l}\text { Mean } \\
\pm S E\end{array}$ \\
\hline Alternaria sn & 5.0 & 3.4 & 0 & 0.2 & 0 & 8.0 & 0 & 16.6 & $3.37 \pm 1.2$ \\
\hline Aspergillus niger & 1,07 & 0 & 0 & 2,8 & 0 & 0 & 0 & 3.87 & $0.55 \pm 0,4$ \\
\hline Fusarium oxysporium & 3,5 & 4,4 & 0 & 0,3 & 0 & 0 & 0 & 8,2 & $1,17 \pm 0,71$ \\
\hline Fusarium $s p$ & 29,0 & 0 & 8,6 & 1,46 & 31,4 & 13,2 & 29,0 & 112,6 & $16,1 \pm 5,1$ \\
\hline Penicillium frequentans & 8,8 & 4,4 & 1,0 & 0 & 0 & 0 & 0 & 14,2 & $2,02 \pm 1,3$ \\
\hline Penicillium steckii & 21,8 & 2,25 & 36,0 & 3,0 & 0 & 10,3 & 0 & 73.35 & $10,47 \pm 5,1$ \\
\hline Phoma glomerata & 23,2 & 0 & 30,2 & 2,0 & 21,8 & 0 & 0 & 77,2 & $11,02 \pm 2,3$ \\
\hline Phoma eupyrena & 6,6 & 0 & 11,0 & 0 & 13,5 & 11,6 & 0 & 42,7 & $6,1 \pm 6,06$ \\
\hline Total & 98,97 & 14,45 & 86,6 & 9.76 & 66,7 & 431 & 29,0 & & \\
\hline Mean \pm SE & $12.37 \pm 3,7$ & $1,8 \pm 0,7$ & $10,82 \pm 5,1$ & $1,22 \pm 0,4$ & $8,34 \pm 4,4$ & $5,38 \pm 2,1$ & $3,62 \pm 3,6$ & & $6,2 \pm 3,46$ \\
\hline
\end{tabular}

$\mathrm{GAL}=$ Gallic acid, $\mathrm{CAF}=$ Caffeic acid, GEN $=$ Gentisic acid VAN= Vanillic acid, CUM $=$ Coumeric acid,

FER $=$ Ferulic acid, 4HB = 4 Hidrox-y Benzoic acid, 4HF = 4 Hidroxy-phenyl propionic acid 


\subsection{Biocides effects on isolated fungi:}

Seven isolated fungal strains of scabs on the outer walls of the cathedral of Salamanca were tested for their growth potential when grown in the presence of biocides. The selected strains belong to the following species: Penicilliurn frequentans Penicillium sp., Aspergillus niger, Trichoderma viride, pseudokoningii, Mucor hiemalis and Fusarium reticulatum. The interest of these microorganisms lies in that they are acidogenic and have shown that in the metabolism of carbohydrates they produce oxalic 'gluconic' citric malic acids, etc. These acids produced by the fungi are responsible for the alteration of the stony materials since they solubilize the mineral cations of the substrate, carry out a selective attack on silicates and feldspars, mainly [18] and are chelation agents of cations $[11,18]$. Actidide biocide was the most effective inhibitors for fungi (Figure, 1). Table 2 shows the Minimum Concentration of each biocide which inhibits fungal growth. It is observed that the minimum concentration of inhibition (MCI) of each product varies with the organism tested. Thus, Mucor hiemalis is resistant to Actidide, Mergal and Preventol, at concentrations of 0.001 and $0.01 \%$, however the fungus shows a high sensitivity to Tego.

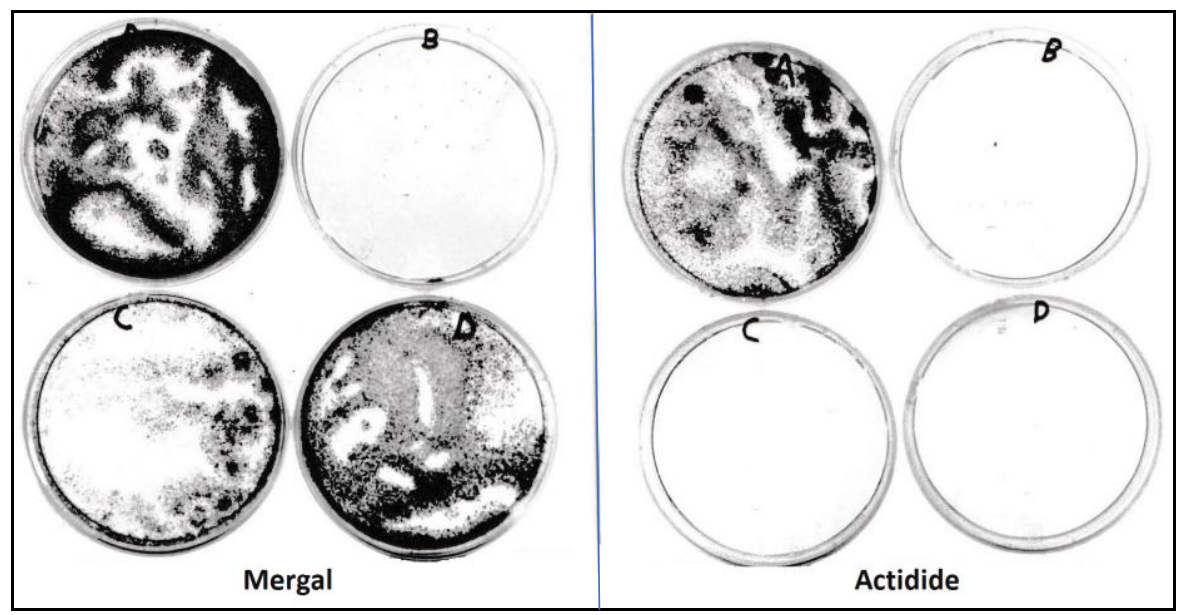

Figure 1: Antifungal activity of Mergal and Actidide against Aspergillus niger at different concentrations. A. control, $\mathrm{B}, \mathrm{C}$ and $\mathrm{D}$, concentrations $0.1,0.01,0.001 \%$, respectively.

Table (2): Minimum Concentration of each biocide which inhibits fungal growth.

\begin{tabular}{|l|l|l|l|c|}
\hline \multirow{2}{*}{ Species } & \multicolumn{4}{|c|}{ Minimum Concentration of biocide (\%) } \\
\cline { 2 - 5 } & ACTIDID & MERGAL & PREVEN & TEGO \\
\hline Penicillium sp & 0,001 & $0, \mathrm{Q} 1$ & 0,001 & 0,1 \\
\hline Penicilliumfrequentans & 0,001 & 0,01 & 0,01 & 0,05 \\
\hline Aspergillus niger & 0,001 & 0,1 & 0,05 & 0,001 \\
\hline Tn'choderma viride & 0,001 & 0,001 & 0,001 & 0,05 \\
\hline Trichodenna p seudokoningii & 0,001 & 0,001 & 0,001 & 0,001 \\
\hline Mucor hiemalis & 0,05 & 0,05 & 0,001 & 0,001 \\
\hline Fusarium reticularum & 0,001 & 0,01 & 0,001 & 0,1 \\
& & & & \\
\hline
\end{tabular}


T. pseudokoningii, on the other hand, is very sensitive to all biocides tested, in such a way that concentrations of $0.001 \%$ are sufficient to prevent the growth of this fungus.

The antifungal potency of each product is reflected in Table 2. There it is observed that under "in vitro" conditions, Actidide is the most effective product and, on the contrary, Tego is the product that requires the highest concentration to inhibit microbial growth, especially for Penicillium and F. reticulatum.

Many factors seem to influence the MIC of a micro-biocide such as the composition of the culture medium, $\mathrm{pH}$, temperature of incubation, inoculum, etc. [19, 20 and 21].

Therefore, after the MIC values of all the fungicides tested were known, 2 strains were selected: Fusarium sp. and Aspergillus niger, which were inoculated on sand samples and in the presence of Actidide since it was the product that showed the highest inhibitory capacity. Inoculation was performed on stone specimens in order to establish conditions closer to the natural environment and to observe the scanning microscope, the degree of inhibition, and the morphological and structural modifications produced in the fungal cell.

\subsection{Electronic microscopy examination of the growth of those fungi on the stones}

When Aspergillus niger was grown on sandstone specimens with sufficient $\mathrm{C}$ and $\mathrm{N}$ content, it grew abundantly, forming a biofilm on the specimen surface, as seen under a scanning microscope (Figure $2 \mathrm{~b}$ ). Thin hyphae are well visible across the field and spores form isolated aggregates. However, when A. niger was grown in the presence of $0.1 \%$ Actidide, concentration at which the fungus was inhibited in Petri dish tests, and added at the same time as the inoculum, growth appears to have been inhibited, the conidia and hyphae, which on the other hand appear altered, (Figure 2a). Then the biocide was applied to the test tube after 7 or 14 days after the growth of the fungus began, the multiplying processes seem to have stopped and the mycelium and conidia observed in Figure 3 would correspond to the cell development produced the days prior to incorporation of the biocide. In addition, there are also crystals, such as the one seen in the lower part of Figure 3 a, probably calcium oxalate, as has been recently verified [22].

When the concentration of the applied biocide was higher, $0.2 \%$, the processes of inhibition followed. With the fungicide added at the same time as the inoculum, it appears that the inhibition is complete (Figure 4 a). When Actidide was added 7 days after the fungal inoculation of the specimens (Figure $4 \mathrm{~b}$ ), it was possible to observe important changes in the mycelium, such as swellings along the hyphae and also at the tips of the hyphae. In other hyphae, there is vesicular ornamentation on the cell wall, which has also been described in Candida parapsilosis [23] These changes ultimately lead to a progressive destruction of cellular architecture [24 and 25]. 
Fusarium sp. cultured on sandstone, for 21 days, it shows, at the scanning microscope, abundant growth, developing a branched mycelium that goes through the holes and existing holes in the rock (Figure 5b). Conversely, when Fusarium $s p$ was grown in the presence of $0.1 \%$ Actidide, important changes must have taken place at the cellular level since growth seems interrupted and the hyphae observed, which must correspond to the inoculum, appear altered, with swellings and formations similar to those described in A. niger (Figure 5a). Figure 6 shows some areas of hyphae affected with very obvious stresses and deformations; in other houses multiform adhesions appear on the hyphae. When Fusarium sp. was treated with concentrations of $0.2 \%$ of the antifungal agent, the structural changes and the morphological modifications were very marked (Figure 7).

These tests that can be considered intermediate between "in vitro" tests and tests on the monument demonstrate the susceptibility of the selected fungal spectra to fungicides as powerful as Actidide.

On the other hand, the biocide added to the indicated concentrations $(0.1$ and $0.2 \%)$ on sandstone samples did not affect the coloration and texture of the stone material, which must be taken into account if what is the aim is to apply it as a micro-biocide on a monument of artistic value.

The next step to be carried out would be the application of 1 biocide limited and controlled surfaces of a monument, laboratory, observing periodically, in tests and the survival of fungal species present on the stone. The concentration of the product it should be variable and small, since in inhibition tests in Petri dishes, Actidide showed ability to inhibit fungal growth at low concentrations such as $0.001 \%$. The efficiency of Actidide due to salicylic acid which reported as one of the most effective agents to control fungal infections [26] (Figure 8).
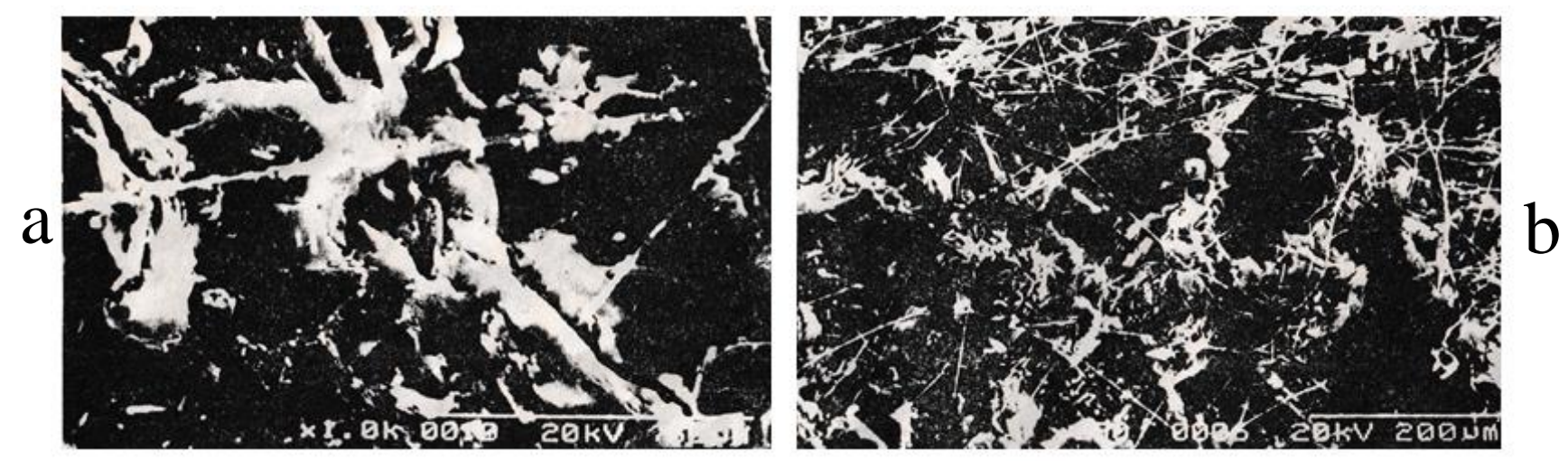

Figure 2: Micrograph of Aspergillus niger growing on sandstone. a) 21 days after treatment with Actidide $0.1 \%$

b) 21 days without treatment. 

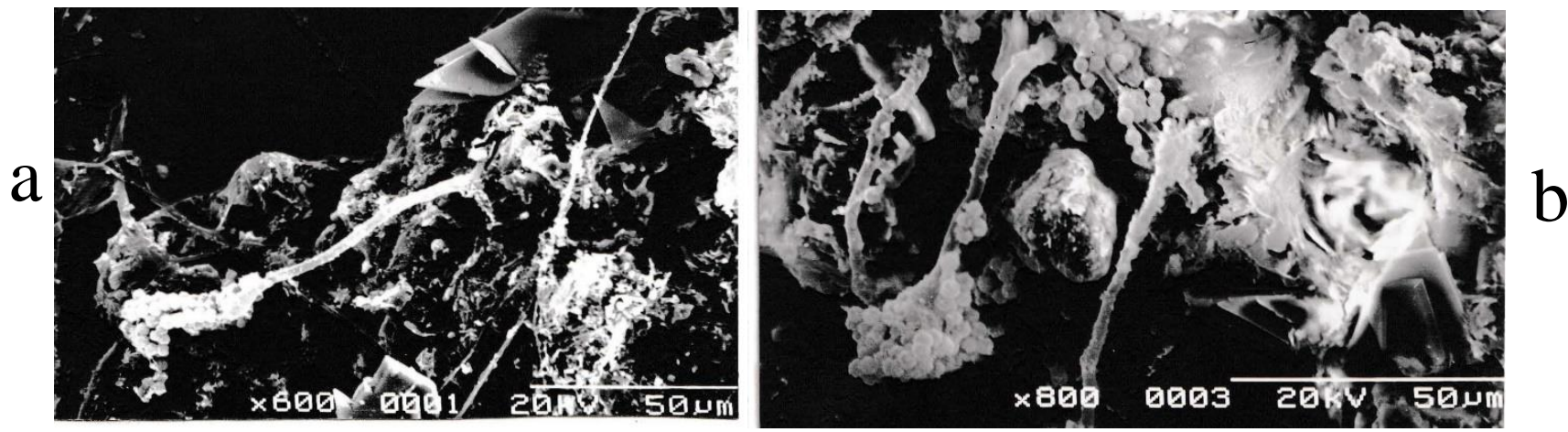

Figure 3:. Micrograph of Aspergillus niger growing on sandstone. a) 7 days after treatment with Actidide $\mathbf{0 , 1 \% , ~ b ) ~} 14$ days after incorporation of the biocide.
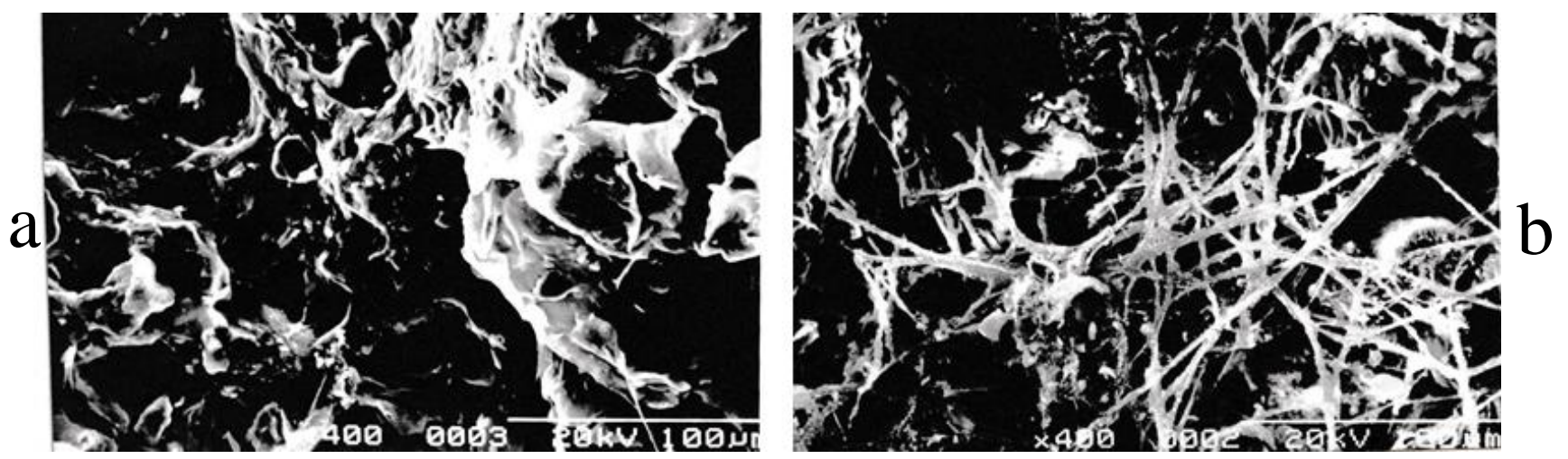

Figure 4: Growth of Aspergillus niger in the presence of $0.2 \%$ Actidide. a) biocide added at the same time as the fungus, $b$ ) added 7 days.
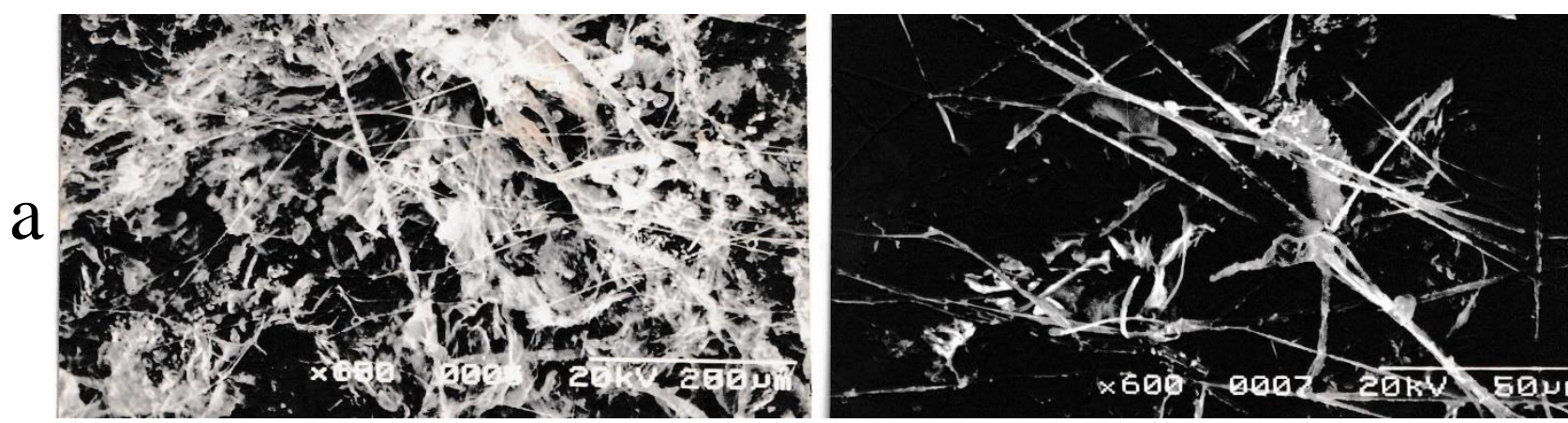

Figure 5: Micrograph of Fusarium sp. growing on sandstone. a) 7days after treatment with Actidide 0.1\%

b) 21 days without treatment. 


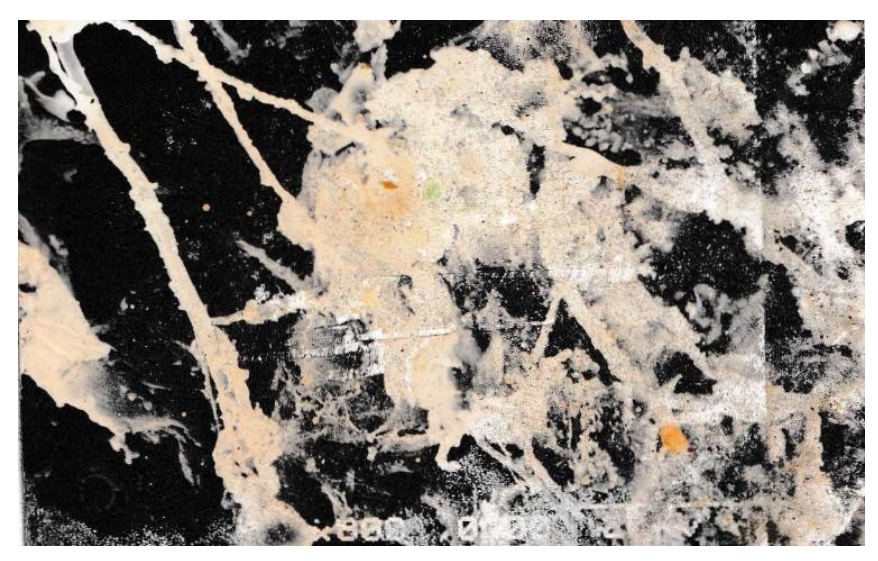

Figure 6: Scanning microscope micrographs of Fusarium sp. growing on sandstone after 14 days of treatment with $0.1 \%$ Actidide.

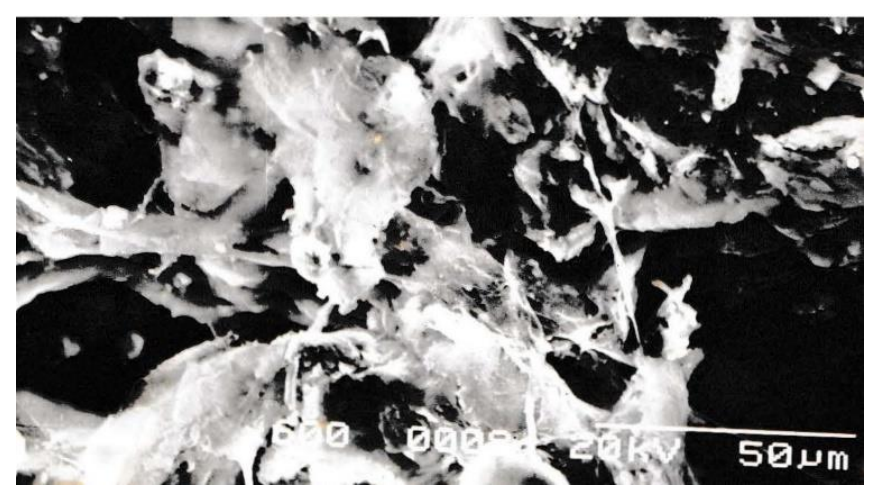

Figure 7: Growth micrograph of Fusarium $s p$ in showing the presence of the $0.2 \%$ Actidide biocide after 7 days of treatment.<smiles>O=C(O)c1ccccc1O</smiles>

Figure 8: Salicylic acid

4. Conclusion: Actidide is one of the most efficient biocides to inhibit fungal growth at low concentrations for stones treatment. It's efficiency due to salicylic. 


\section{References}

[1] Fassina,V. (1988). Biodeterioration of stone: The Deterioration and Conservation of Stone. L. Laz zarini, R. Pieper, eds . Unesco, Venecia, pp. 111-151.

[2] Ericsson, P.; Johansson, L-G and Lindquist 0. (1988). Chemical mechanisms of corrosion degradation of stones and metals. In : Segundo Congreso Eurocare, Sevilla, pp 2- 12 .

[3] Warscheid,T., PETERSEN,K., KRUMBEIN,W.E. (1988). Physiological characterization of chemoorganotrophic bacteria isolated from sandstones. En: Proc. VI th Int. Congr. Deterioration and Conservation of Stone, Torun. Nicholas Copernicus University, pp. 26-32.

[4] Hendersson, M.E.K. and Duff, R.B. (1963). The release of metabolic and silicate ions from minerals, rocks and soils by fungal activity. J. Soil Sci. 1_1, 236-246.

[5] Strzelczyk, A. B. (1981). Stone. in: Economic Microbiology. A .H. Rose ,ed. Academic Press, London, pp. 61-80.

[6] de la Torre, M.A.;Gomez-Alarcon, G.; Melgarejo , P., Lorenzo,J. (1991). Fungal colonization of the Salamanca cathedral sandstone. Some patterns of degradation. En: Science, Technology and European Cultural Heritage. N. S. Baer, C. Sabbioni, A .I . Sors, eds . Butterworth -Heinem ann Ltd, Oxford, pp . 5 11-5 14.

[7] Saiz-Jimenez,C. (1984). Weathering and colonization of limestones ln an urban environment. En: Soil Biology and Conservation of the Biosphere. J. Szegied., Akademia. Kiad6, Budapest, pp. 757-767 .

[8] Eckhardt, F.E.W.(1988). Influence of culture media employed in studying microbial weathering of building stones and monuments by heterotrophic bacteria and fungi. in: Proc. V Ith Int. Congress Deterioration and Conservation of Stone. Nicholas Copernicus Univ., Torun, pp. 71-81.

[9] Palmer R.J., Siebert, J., Hirsch, P. (1991). Biomass and organic acids in sandstone of a weathering building: Production by bacterial and fungal isolates. Microbial Ecol ogy 21' 253266.

[10] de la Torre, M.A. ; Gomez-Alarcon, G.; Melgarejo , P. and Saiz-Jimenez, C. (1991) .Fungi in weathered sandstone from Salamanca cathedral. Spain. Sci. Total Environ. 107, 159- 168.

[11] Caneva, G and Salvadori, O. (1988). Biodeterioration of Stone. In : The Deterioration and Conservation of Stone. L. Lazzarini, R . Pieper, ed s . Unesco, V enecia, pp. 182-234.

[12] Parkinson, D. Gray . T.R.G. and Williams. S.T. (1971). Methods for Studying the Ecology of soil microorganisms. Black·well Sci. Pub.. Oxford

[13] Whitehead, D.C. (1964). Identification of p-hydroxybenzoic, vanillic, p -coumaric and ferulic acids in soils. Nature, 202, 417-418.

[14] Manley ,E.P and Evans,L.J. (1986). Dissolution of feldspars by low-molecular-weight aliphatic and aromatic acids. Science 141, 106-112. 
[15] Martin, J .P and Haider ,K. , (1969). Phenolic polymers of Stachybotrys atra, Stachybotrys chartarum and Epicoccum nigrum in relation to humic acid formation. Soil Science 107, 260270.

[16] Beveridge , E .G and Hugo,W.B. (1964). The resistance of gallic ac id and its alkyl esters to attack by bacteria ab le to degrade aromatic ring structures. J . App 1. Bac t. 2 7, 304-3 11.

[17] Robert T ,M. and Razzaghe-Karimi,M.H. (1975). Mise en evidence de deux type s d 'ev o lu t ion mineralogique des micas trioctaedr iques en presence d'acides organiques hydrosolubles. C.R . Acad . Sci. Paris 280 . 2175-2178 .

[18] G Gómez-Alarcón and M A de la Torre. 1994. Mechanisms of microbial corrosion on petrous materials. Microbiología (Madrid, Spain) 10(1-2):111-20

[19] Pereiro S,M, Pereiro Jr ,M., Pereiro,M . (1992). Estudio de la activ idad fungistati ca del Sertaconazol e in vitro frente a Trich ophyt on rubrum . Rev . Ibe roam . Micol. 12-16

[20] Kakakhel, M.A.; Wu, F.; Gu, J.D.; Feng, H.; Shah, K.; Wang, W. (2019) Controlling biodeterioration of cultural heritage objects with biocides: A review. Int. Biodeterior. Biodegrad, 143, 104721.

[21] Pfendler, S, Borderie, F, Bousta F, Alaoui-Sosse L, Alaoui-Sosse,B, Aleya, L. (2018). Comparison of biocides, allelopathic substances and UV-C as treatments for biofilm proliferation on heritage. monumentsJournal of Cultural Heritage 33, 117-124

[22] de la Torre,M.A. (1992). Estudio de la par ticipaci6 n de los hongos filamentosos en los procesos de biodeterioro de los monumentos petreos . Tesis doctoral Universidad Autonoma de Madrid.

[23] Meingassner, J.G., Sleytr, U.B. (1982). The effects of naftifine on the ultrastructure of Candida parapsilosis: a freeze fracture study. Sabouraudia 20, 199-207.

[24] Malle, M., Butty, P., Montes, B., Jouvert, S. and Bastide, J.M. (1992). Antifungal activity of naftifine against various yeast and dermatophytes: determination of minimal inhibitory concentration and revelation of cell wall alterations by scanning electron microscopy. Can J. Microbial.37, 964-970.

[25] Sheir, D , Osama Amer, Waill A. Elkhateeb and Ghoson M. Daba. (2020). Elucidation of Myco-deterioration affecting Calcareous Construction Materials of the Egyptian Architectural. BOREAL ENVIRONMENT RESEARCH, 25(3) 27-56.

[26] Khan, A., Zafar Iqbal and Muhammad Atiq.(2020)2 Evaluation of Organic Acids to Determine Antifungal Potential against Green Mold of Citrus (Kinnow Mandrin) Caused by Fungus Penicillium Digitatum (Pers. Fr.) Sacc. Pakistan Journal of Agricultural Research, Vol.33, Iss.1, 47-55 